\title{
PRODUÇÃO DE BIOCOMBUSTíVEIS E SEGURANÇA ALIMENTAR
}

Bruno César Góes ${ }^{1}$, Jhonatan Cabrera Piazentin², Luís Roberto Almeida Gabriel Filho $^{3}$, Fernando Ferrari Putti ${ }^{4}$, Camila Pires Cremasco Gabriel ${ }^{5}$

${ }^{1}$ Mestrando do Programa de Pós Graduação em Agronegócio e Desenvolvimento da Universidade Estadual Paulista Júlio de Mesquita Filho, UNESP, Campus de Tupã, SP - Brasil, bruno.goes@unesp.br

${ }^{2}$ Mestrando do Programa de Pós Graduação em Irrigação e Drenagem da Universidade Estadual Paulista Júlio de Mesquita Filho, UNESP, Campus de Botucatu, SP - Brasil

${ }^{3,4,5}$ Prof. Dr. da Faculdade de Ciências e Engenharia da Universidade Estadual Paulista Júlio de Mesquita Filho, UNESP, Campus de Tupã, SP - Brasil

Recebido em: 22/09/2018 - Aprovado em: 23/11/2018 - Publicado em: 03/12/2018 DOI: 10.18677/EnciBio_2018B67

O direito à Segurança Alimentar é um dever do Estado. A garantia por alimentos em quantidade, qualidade e diversidade é direito de todas as pessoas. Dados da Organização Nações Unidadas (ONU) mostram que a população mundial está aumentando de forma intensa. Nesse sentido existirá uma demanda pelo aumento da produção de alimentos para suprir as necessidades dessas populações. Em paralelo a isso, temos a necessidade de produção de energia limpa para suprir esse aumento populacional. No Brasil, a produção de energia produzida a partir da canade-açúcar teve um aumento expressivo a partir da evolução da produção de veículos flex. Desde então as áreas destinadas ao plantio da cultura de cana-de-açúcar para a produção de etanol vêm aumentando, concorrendo com as áreas destinadas à produção de alimentos. Esse trabalho contextualiza se a produção de cana-deaçúcar para a geração de energia e a produção de biocombustíveis impacta na Segurança Alimentar no Brasil. Existem diferentes visões que norteiam as considerações finais desse trabalho, sendo que a principal vertente está relacionada à melhoria na produtividade das terras destinadas à produção de alimentos, por meio da intensificação do uso de tecnologias, uma vez que essas terras estão sendo disputadas com as produções de matérias primas que se destinarão à produção de biocombustíveis e alimentos.

PALAVRAS - CHAVE: Cana-de-Açúcar, Disponibilidade de Terras, Produção de Alimentos.

\section{PRODUCTION OF BIOFUELS AND FOOD SAFETY}

\begin{abstract}
The right to Food Security is a duty of the State. The guarantee for food in quantity, quality and diversity is the right of all people. UN data show that the world's population is increasing sharply. Thus, there will be a demand to increase food production to meet the needs of these populations. In parallel to this, we have the need to produce clean energy to supply this population increase. In Brazil, the production of energy produced from sugarcane increased significantly from the
\end{abstract}


evolution of flexfuel vehicle production. Since then, the areas destined to the planting of the sugar cane culture for the ethanol production have been increasing, competing with the areas destined to the production of foods. Discussing this theme, this paper contextualizes if the production of sugar cane for the generation of energy impacts on Food Security in Brazil. There are different views that guide the final considerations of this work, and the main aspect is related to the improvement in the productivity of lands destined to food production, through the intensification of the use of technologies, since these lands are being disputed with the productions of which will be used for the production of bio-fuels and food.

KEYWORDS: Sugar cane, Land Availability, Food Production.

\section{INTRODUÇ̃̃O}

Segundo dados da Organização das Nações Unidas para a Alimentação e Agricultura (FAO, 2015), o número de pessoas sem alimentação no mundo é de aproximadamente 805 milhões, o que provocará nas décadas futuras um aumento acelerado por procura e consumo de alimentos. Segundo a Declaração Universal dos Direitos Humanos (ONU, 2016) a Segurança Alimentar é um direito do cidadão e um dever do Estado, que deve disponibilizar alimentos saudáveis, facilitando seu acesso a todos. Toda pessoa tem direito a alimentação e a elementos básicos de forma que sejam supridas suas necessidades, que assegurem a ele e sua família um padrão de vida digno. $O$ acesso à energia, um dos temas centrais desse trabalho, é um desses elementos básicos, que complementarmente, contribuem para o estabelecimento de um melhor bem-estar das pessoas e ajudam na promoção do seu desenvolvimento (ONU, 2016).

Este estudo parte da compreensão de que todos, sejam indivíduos ou grupos, devem ter pelo menos o mínimo básico necessário para alcançar um patamar mais elevado em sua qualidade de vida, e que os acessos à alimentação de qualidade e à energia são aquisições que ajudam muito nisso.

Essa compreensão deve perpassar ainda pelo aumento da população, e pela disponibilidade de terras, que podem ser ocupadas com a produção de alimentos e que também podem ser ocupadas com a produção de cana-de-açúcar como matéria prima usada para a geração de energia. Não foi um objetivo desse trabalho analisar outras fontes de energia.

Essa situação, que vem propiciando discussões e pesquisas, tem gerado opiniões diferentes entre os estudiosos, sem conclusões muito bem definidas. O problema se a ocupação do solo com a produção da cana-de-açúcar para geração de energia e produção de açucar pode impactar negativamente na ocupação do solo para produção de culturas alimentares, a ponto de ser uma ameaça à segurança alimentar é uma questão bastante emblemática, que dá base á muitas interpretações e vertentes diferentes.

Procurando contribuir, esse trabalho, com o seu objetivo, se propõe contextualizar sobre o problema apresentado, identificando pontos relevantes entre os temas centrais, ressaltando aqui como foco do estudo a produção da cana-deaçúcar como principal matéria-prima para a produção de etanol.

Esse trabalho que usa a pesquisa bibliográfica investiga a fundamentação teórica por meio de literatura pertinente, considerando as informações coletadas como referências, relacionando-as com o problema aqui exposto. A revisão realizada fez uso de bases científicas como Scopus, Scielo, Web of Science, procurando destacar as publicações mais recentes, além de dados oficiais de instituições de pesquisas. 
Esse estudo se justifica pela importância sempre atual dos seus temas, apresentando a Produção de Energia e a Segurança Alimentar como situações fundamentais na vida dos seres humanos, mas que concorrem entre si em suas bases produtivas, disputando a ocupação de solos agricultáveis.

\section{DESENVOLVIMENTO}

O processo de desenvolvimento de um país é composto por vários elementos, porém, existe o entendimento de que o mesmo não pode ser avaliado apenas por seu componente econômico, pois somente esse aspecto não pode explicar a dinâmica das mudanças sociais, senão de maneira limitada (FURTADO, 1961).

Nesse sentido, a dimensão humana do desenvolvimento fundamenta-se na valorização das pessoas, que supõe crescimento econômico não como fim, mas como meio para reduzir as privações e as aflições humanas (FRANCO, 2000).

É quase unânime compreender que o desenvolvimento, atualmente, não está relacionado unicamente ao crescimento econômico, mas também com outras dimensões que devem ser consideradas e avaliadas, pois estão interligadas. Hoje se aceita que o desenvolvimento "deve ter como efeito, melhorar a vida de cada pessoa" (desenvolvimento humano); de todas as pessoas (desenvolvimento social); das que estão vivas hoje e das que viverão no futuro (desenvolvimento sustentável) (FRANCO, 2000).

A expressão desenvolvimento sustentável se fortaleceu mais a partir de 1992, quando aconteceu a elaboração da Agenda 21, como resultado da "Conferência das Nações Unidas sobre Meio Ambiente e Desenvolvimento", realizada no Rio de Janeiro, com a presença de aproximadamente 179 países, com o propósito de procurar as causas reais dos problemas ambientais, sociais e econômicos e contribuir com a resolução deles, através de planejamentos participativos envolvendo a sociedade em suas localidades (MMA, 2014).

Com foco também desenvolvimentista, os Objetivos do Desenvolvimento Sustentável (ODS) foram definidos em 2015, pela ONU - Organização das Nações Unidas juntamente com seus Estados-membros e representantes da sociedade civil, contemplando metas de realização até 2030 , através de atividades que os países devem procurar executar adequando-as à suas realidades na tentativa de se buscar um futuro melhor para o mundo como um todo (ONU, 2015).

Os ODS (Objetivos do Desenvolvimento Sustentável) são grandes metas que foram revisadas, ampliadas e organizadas numa agenda, a partir dos Objetivos do Desenvolvimento do Milênio (ODM's), devendo contribuir para o desenvolvimento sustentável global, elevando os patamares de melhoria de vida das pessoas, principalmente daquelas que se encontram em situações críticas, de vulnerabilidade e de muito pouca ou quase nenhuma possibilidade de desenvolvimento humano (ONU, 2015).

Dentre esses objetivos, dois deles estão diretamente ligados a esse estudo, pois têm como propósito a Segurança Alimentar e a Energia, que serão os temas centrais abordados nesse trabalho, sendo: objetivo 2: Acabar com a fome, alcançar a segurança alimentar e melhoria da nutrição e promover a agricultura sustentável; e o objetivo 7: Assegurar o acesso confiável, sustentável, moderno e a preço acessível a energia para todos (ONU, 2015).

Nesse contexto bastante atual, apresenta-se o conceito de Segurança Alimentar, que apesar de usados na Europa desde a primeira guerra mundial (19141918) e caracterizado como a produção dentro das fronteiras de um país para proteger a sua população contra a fome em tempos de crises políticas, torna-se 
mais conhecido a partir de 1945, com a constituição da Organização das Nações Unidas - ONU e suas comissões.

Apresentavam-se naquela época, os que defendiam como direito humano o fato de se ter acesso ao alimento e os que entendiam que esse mesmo acesso deveria ser garantido através do mercado (ABRANDH, 2013).

Tanto no Brasil como em todos os outros países, o tema Segurança Alimentar vem sendo discutido com interesses e entendimentos diferentes, desde o fim da Segunda Guerra Mundial (1945), até aproximadamente 1974, período esse em que o mundo passou por escassez de alimentos e desarmonia política (período pósguerra). Havia, nessa época, a compreensão de que a insegurança alimentar que ocorria era consequência de uma baixa produção de alimentos nos países mais pobres, e na tentativa de reverter esse quadro, foram criadas iniciativas para a agricultura em alguns países (ABRANDH, 2013).

$\mathrm{Na}$ busca por uma definição mais adequada, passando inclusive por muitas discussões a respeito, com a apresentação do Documento Final da I Conferência Nacional de Alimentação e Nutrição (1986), a Segurança Alimentar passa a ser entendida no Brasil como sendo "a garantia, a todos, de condições de acesso a alimentos básicos de qualidade, em quantidade suficiente, de modo permanente e sem comprometer o acesso a outras necessidades básicas, com base em práticas alimentares que possibilitem a saudável reprodução do organismo humano, contribuindo, assim, para uma existência digna" (SILVA, 2014).

\section{Aumento Populacional e Consumo de Alimentos}

Apesar dos dados apresentados pela História até agora, o fato é que desde o final da Segunda Guerra Mundial, o aumento da produção de alimentos do planeta cresceu muito, além do aumento da própria população mundial.

Os números apresentados em relatórios da ONU (2012) mostram que as mudanças demográficas estão ocorrendo de forma intensa e que atualmente na Terra, existem aproximadamente 7,2 bilhões de habitantes, com perspectivas de crescimento para 2025 de 8,1 bilhões e para 2050, em 9,6 bilhões de pessoas (maior concentração nos países em desenvolvimento), gerando preocupação e dúvidas sobre a questão da disponibilidade de alimentos para essa população. Conforme pode ser observado o aumento populacional do mundo em cenários diferentes de perspectiva de crescimento até 2100 (Erro! A origem da referência não foi encontrada.).

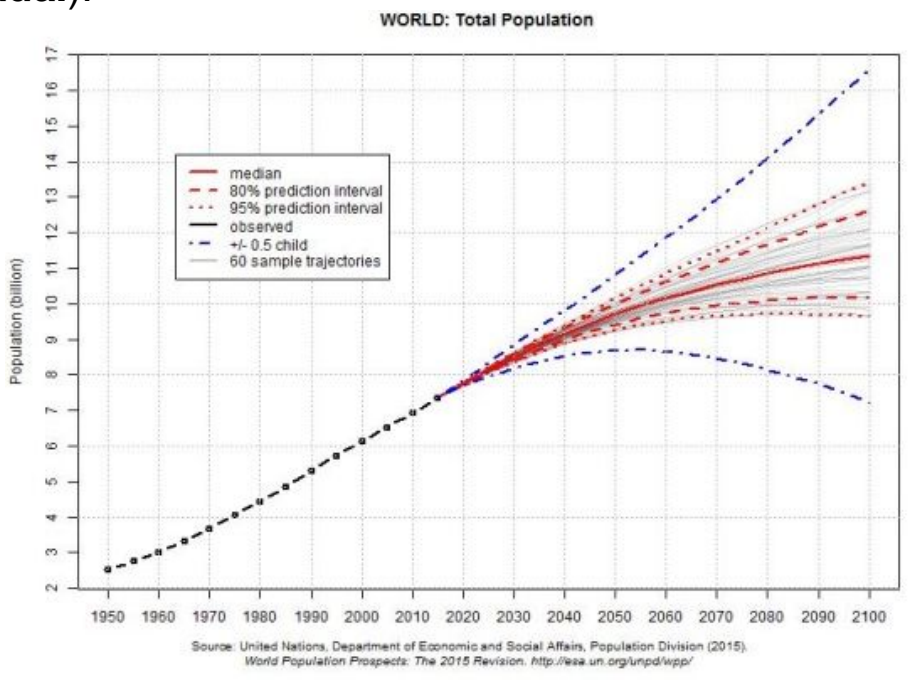


FIGURA 1. Perspectiva do aumento da população mundial até 2100. Fonte: (ONU, 2015).

Outro fator importante, paralelo ao aumento da população, é que a urbanização também está aumentando. A concentração nas cidades passou de 746 milhões em 1950 para 3,9 bilhões em 2014 e esse movimento deve continuar sendo o maior percentual de urbanização no mundo está na Ásia, com 53\%, seguido pela Europa, com um percentual de $14 \%$, e por último a América Latina e o Caribe que, juntos, tem $13 \%$ da sua população concentradas em suas áreas urbanas (ONU, 2012).

Quando dados referente ao aumento populacional são apresentados, torna-se importante trazer a discussão também, a Teoria de Malthus, que discorre sobre a possibilidade de acontecer um crescimento desenfreado da população mundial e não acontecer, na mesma proporção, a oferta e disponibilidade de alimentos suficientes para essas pessoas, podendo em consequência a isso, ocorrer uma forte escassez de alimentos e uma crise de fome muito grande entre os povos (MALTHUS, 1996).

Vem sendo discutida, a questão do crescimento da população e da possível falta de alimentos, o que poderia causar uma calamidade no mundo, porém, Abramovay (2010), considera as hipóteses apresentadas como um equívoco, mas não desconsidera que os caminhos perseguidos pelo homem para aumento da produção e produtividade de alimentos culminou com a falta de cuidados e de preservação com o meio ambiente e seus recursos, que são finitos.

Hoje, ainda que permaneça sem solução a questão da fome, e apesar de algumas crises alimentícias que aconteceram no mundo, o que se observa é que a Teoria de Malthus (1996) não aconteceu da forma como ele previa (BUAINAIN et al., 2016). O número de pessoas aumentou em virtude do acréscimo no percentual da longevidade, resultando em maior consumo de alimentos, porém, no mesmo ritmo, houve um aumento da produtividade na produção dos alimentos não acontecendo um colapso na segurança alimentar (FAO, 2015).

\section{Biocombustíveis}

A questão da produção de energia por fontes menos poluentes, tem apresentado grande interesse nos últimos anos. Destaca-se dentre essas fontes, a produção energética oriunda dos biocombustíveis, nos quais contribui para redução de emissão dos gases causadores do efeito estufa, havendo um menor impacto no meio ambiente além de reduzir a dependência em relação aos combustíveis fósseis, recursos não renováveis (GURGEL, 2011). Porém, desde a década de 1980, cientistas de todo o mundo vem alertando os Governos sobre a elevação da temperatura da Terra, ocasionada pelo fenômeno do aquecimento global, em função da queima dos combustíveis fósseis; o que se faz de grande interesse a pesquisa por fontes menos poluentes como é o caso dos biocombustíveis (LEITE; LEAL, 2007).

No entanto conforme Matos et al., (2008) a expansão da produção dos biocombustíveis tem mudado significativamente a forma efetiva do uso da terra, havendo assim, uma redução da produção agrícola de alimentos em substituição da matéria-prima para os biocombustíveis, inflacionando os preços dos produtos alimentícios (MITCHELL, 2008). O Brasil por sua vez, possui grande competitividade 
em relação à produção de energia decorrente de produtos agrícolas, do qual é sobrado de recursos naturais e tecnológicos (MARTINELLI; FILOSO, 2008).

Entende-se por biocombustível todas as fontes de energia, seja ela nos estados físicos sólido, líquido ou gasoso; e proveniente de matéria biológica e não fóssil, dando destaque para a produção etanol (produto da cana-de-açúcar) e biodiesel, atualmente os únicos em escala comercial no mundo na ordem de 50 bilhões de litros e 5 bilhões de litros por ano respectivamente (LEITE; LEAL, 2007; UNCTAD, 2008; ANAP, 2017).

A potencialidade do Brasil para a produção dos biocombustíveis é enorme no que diz respeito, à produção de etanol, sendo as regiões Sudeste e Centro-Oeste as que se apresentam como maiores produtoras da cultura da cana-de-açúcar, e produção de biodiesel, por meio das oleaginosas, destacando-se com grande expressividade a região Nordeste, com o cultivo da mamona, amendoim, gergelim, babaçu para a extração do biodiesel além do cultivo tradicional da cultura da canade-açúcar. O Norte por sua vez, se desponta como produtor de dendê, com mais de 50 milhões de hectares disponíveis para o plantio da cultura (PEREZ et al., 2005; SILVA, 2013; CONAB, 2016).

A produção do biodiesel, mesmo mostrando-se uma viabilidade para sua extração, foi apenas na década de 1990 que expandiu sua produção devido a reestruturação da matriz energética no país, sendo somente em 1998 liberado para testes e comercializações pela Agência Nacional do Petróleo - ANP, criado posteriormente o Programa Brasileiro de Biocombustíveis - Probiodiesel (SILVA, 2013).

Por sua vez, a questão do etanol começou a ser fortemente introduzida no Brasil em 1975, quando devido à primeira crise mundial do petróleo, o governo brasileiro criou o Programa Nacional de Álcool, o "Proálcool", em que estabelecia uma mistura obrigatória do etanol anidro com a gasolina para o combustível da frota nacional; sendo lançado no ano de 1979 o primeiro carro movido à etanol hidratado (OCDE-FAO, 2015). Porém, após esse período, quando superada a crise do setor petrolífero e consequentemente havendo a queda do preço do barril de petróleo, a produção de etanol perdeu espaço frente à competitividade do combustível fóssil (LEITE; LEAL, 2007).

No entanto, foi após o ano de 2003, decorrente do investimento no setor dos transportes com o lançamento dos veículos com motores bicombustíveis, funcionamento a álcool e/ou gasolina, o momento da retomada para a expansão da produção da cultura da cana-de-açúcar no Brasil, com a exploração dos biocombustíveis, mais precisamente o etanol (NASS et al., 2007).

O sucesso dos veículos flexfuel foi tanto, que em apenas oito anos de lançado, representava $49 \%$ da frota nacional dos veículos leves, correspondente a um total 15 milhões de unidades, com um potencial de alcance de $78 \%$ da frota brasileira no ano de 2020 (TOLMASQUIM, 2012).

Segundo Tolmasquim (2012), as perspectivas mediante o aumento da demanda do etanol, será suprida pelo aumento da área do plantio da cana-deaçúcar, conjuntamente com a implantação de novas tecnologias no setor aumentando a produtividade de toda a cadeia.

\section{Produção de Etanol}

O etanol é atualmente o biocombustível de maior produção mundial, com escala na ordem de 26,5 bilhões de galões produzidos no ano de 2016 , dos quais 
possui os EUA como maior produtor seguido pelo Brasil, sendo os dois países responsáveis por mais de $85 \%$ da produção mundial de etanol como pode-se observar a seguir ().

), o volume da produção de etanol em galões ( 1 galão $=3,78541178 \mathrm{~L}$ ) em 2016 (KOHLHEPP, 2010).

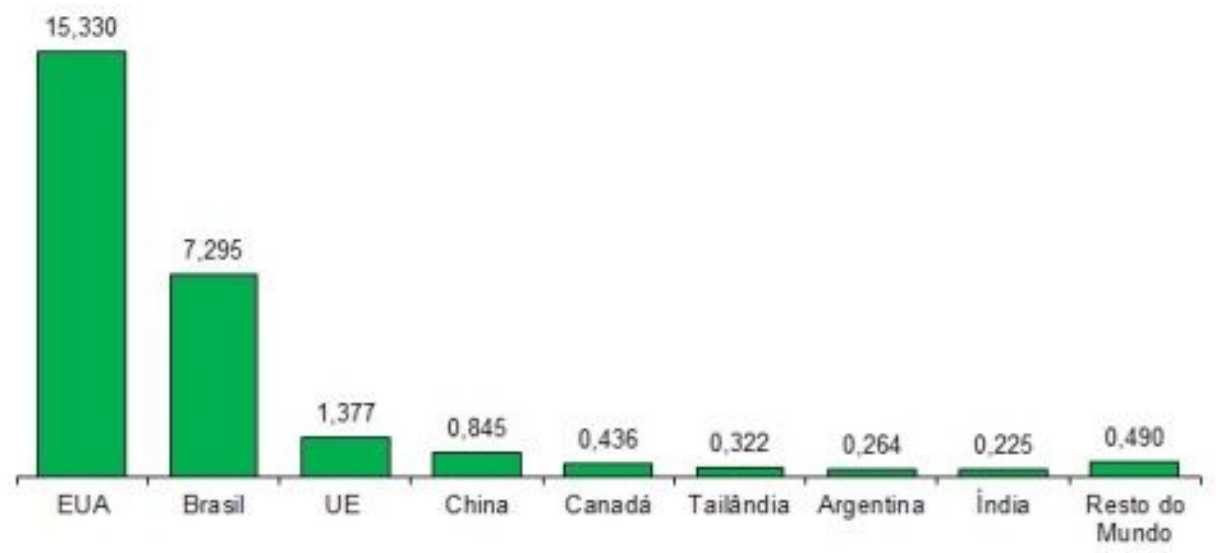

FIGURA 2. Produção de etanol em 2016 (bilhões de galões). Fonte: (RFA, 2016)

O processo de produção do etanol tem sido a principal rota industrial em todo - mundo. Seu processo pode ser denominado microbiológico, ou também fermentação alcóolica e pode ser obtido através da fermentação de açúcares pelas mais diferentes culturas, como a cana-de-açúcar, conforme Lopes et al., (2016) no caso do Brasil aferindo uma produtividade média de 6.500 litros/ha; milho nos Estados Unidos com produtividade em cerca de 3.800 litros/ha e nos países europeus de matéria-prima como a beterraba e trigo, obtém uma produtividade média de 5.400 litros por hectare (BASTOS, 2007; MILANEZ et al., 2014).

O Brasil ocupa a primeira posição em relação à produção de cana-de-açúcar com um total de 736 milhões de toneladas em 2014, seguido pela Índia e China com totais em 352 milhões e 125 milhões de toneladas respectivamente. Na mesma sequência, são suas posições em relação à área destinada para produção da cultura, na ordem de 10,4 milhões, 5,02 milhões e 1,76 milhão de hectares destinados ao plantio da cultura da cana-de-açúcar, como pode-se observar na

TABELA (FAO, 2016).

TABELA 1. Produtividade da cana-de-açúcar por hectare.

\begin{tabular}{|c|c|c|c|}
\hline País & $\begin{array}{l}\text { Produção } \\
\text { (milhões } \\
\text { toneladas) }\end{array}$ & $\begin{array}{l}\text { Área (milhões de } \\
\text { hectare) }\end{array}$ & $\begin{array}{l}\text { Produtividade } \\
\text { (ton./ha) }\end{array}$ \\
\hline $1^{\circ}-$ Brasil & 736,1 & 10,4 & 70,6 \\
\hline $2^{0}-$ Índia & 352,1 & 5,0 & 70,2 \\
\hline 3 - China & 125,6 & 1,7 & 71,3 \\
\hline $4^{\circ}$ - Tailândia & 103,7 & 1,3 & 76,6 \\
\hline $5^{\circ}$ - Paquistão & 62,8 & 1,1 & 55,1 \\
\hline
\end{tabular}

Fonte: Elaborada pelos autores com a base de dados. Fonte: (FAO, 2016).

No entanto, destaca-se que no Brasil, a evolução da produção entre o período de 1976 a 2015, aumentar expressivamente de 103,2 milhões para 736,1 ENCICLOPÉDIA BIOSFERA, Centro Científico Conhecer - Goiânia, v. 15 n.28; p.833 
milhões de toneladas, demandando um aumento da área de plantio em 397,7\%, ultrapassando os 10 milhões de hectares (PEREZ et al., 2005; FAO, 2016). Observa-se na Figura 3 a evolução histórica da área cultivada em relação à produção no período acima.

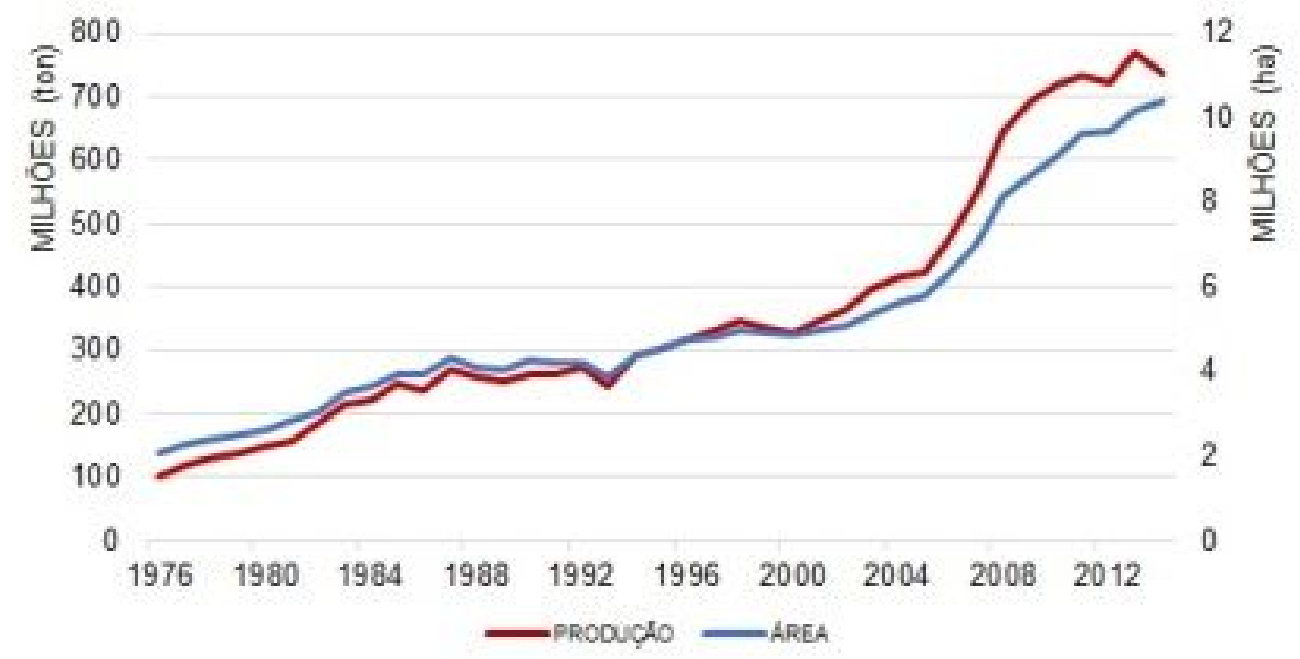

FIGURA 3. Área/Produção da cultura da cana-de-açúcar no Brasil (1976 - 2014).

Fonte: (FAO, 2016)

Dessa forma, atualmente, tem-se o estado de São Paulo como o maior produtor da cultura de cana-de-açúcar no país, com uma área de plantio estimada em 4,67 milhões de hectares, o que representa em média $45 \%$ da área cultivada no Brasil (CONAB, 2015; FAO 2016). Conforme é possível observar na TABELA 2:

TABELA 2. Comparativo de área, produtividade e produção da cultura da cana-de-açúcar (Safra 2015/16).

\begin{tabular}{l|l|l}
\hline Região / UF & Área (mil ha) & Produção (milhões ton.) \\
\hline Norte & 50,3 & 3,5 \\
\hline Nordeste & 947,0 & 52,5 \\
\hline Centro-Oeste & $1.816,2$ & 141,3 \\
\hline Sudeste & $5.584,8$ & 417,5 \\
\hline \multicolumn{1}{c}{ São Paulo } & $4.678,7$ & 350,6 \\
\hline Sul & 597,2 & 44,9
\end{tabular}

Fonte: Adaptada pelos autores. Fonte: (CONAB, 2015).

O crescimento da produção de cana-de-açúcar observado após o ano de 2003 pode-se associar ao ano de introdução dos veículos flexfuel no mercado brasileiro, no qual se resultou num salto de participação de vendas no mercado do setor automotivo de 3,9\% no ano de 2003 para quase 90\% em 2007 - Erro! A origem da referência não foi encontrada.. 


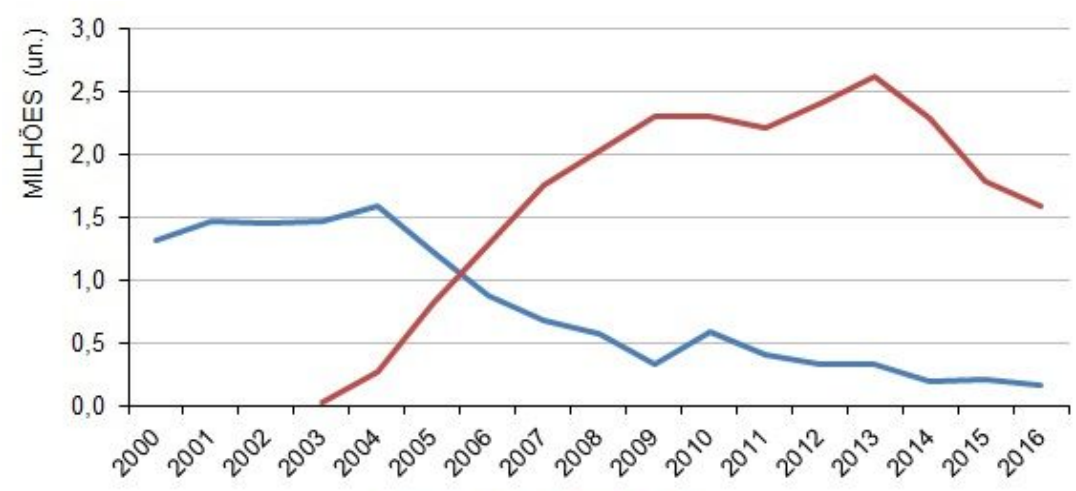

FIGURA 4. Produção de veículos à gasolina e flexfuel (2000 - 2016). Fonte: (SHIKIDA, 2014).

Desse modo viu-se a produção de veículos do tipo flexfuel crescer no mesmo período $4.327,5 \%$, partindo de 39.853 veículos bicombustíveis para 1.764.494 veículos em 2007, enquanto a produção de veículos movido somente à gasolina, despencou para 174.506 no ano de 2016 (ANFAVEA, 2017).

\section{Produção Agrícola e a Produção de Biocombustível}

O Brasil pela sua extensão territorial e exponencial aumento populacional, encontra-se na vanguarda do processo de busca por energia limpa. Além de possuir uma diversidade de usinas hidrelétricas, o país é pioneiro em possuir um programa de veículos com motores que utilizam fontes energéticas limpas e renováveis, nesse caso, trata-se do álcool combustível (álcool hidratado) e do álcool com adição de gasolina em um percentual significativo (álcool anidro) (CHAGAS et al., 2008; FOREST et al., 2014).

Dessa forma, no Brasil, existe um detalhamento da produção energética, que é anualmente publicado pela Empresa de Pesquisa Energética (EPE) conjuntamente com o Ministério de Minas e Energia (MME), e mostra a evolução participativa das diferentes fontes de produção de energia ao longo dos anos.

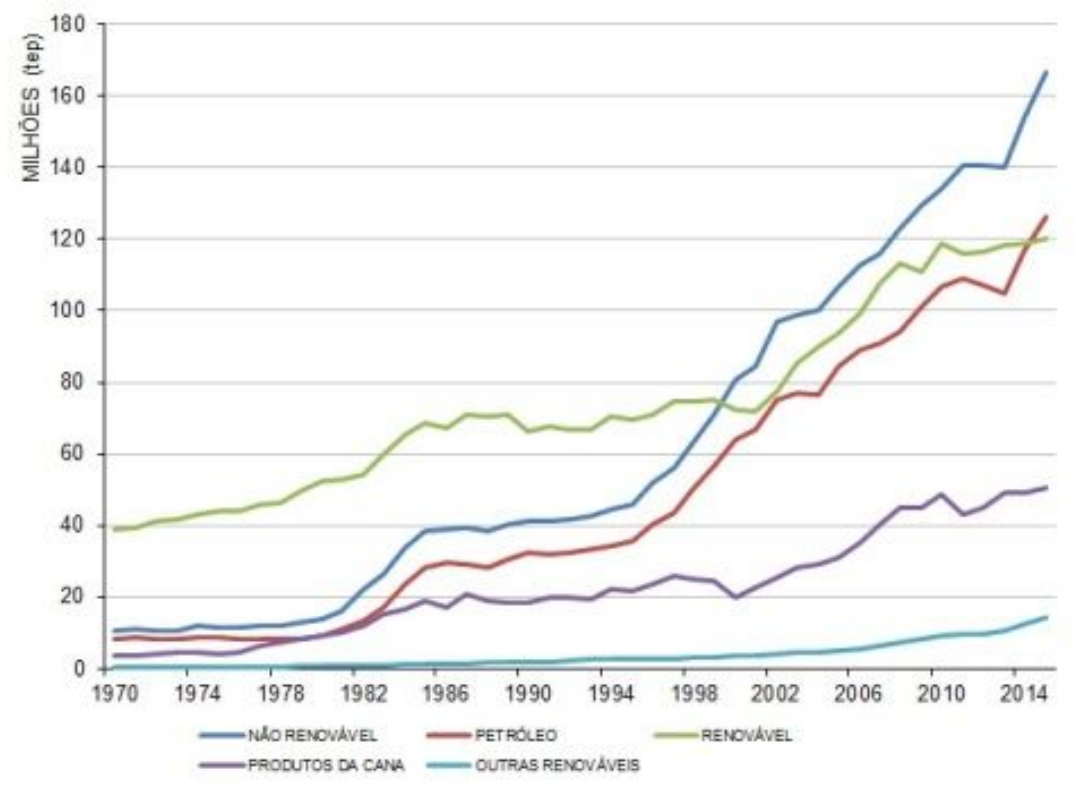

FIGURA 5. Produção de energia primária do Brasil. Fonte: (EPE, 2015). 
Assim observa-se a evolução da produção de energia primária no Brasil, em que há o domínio das fontes não renováveis na ordem de 166 milhões TEP, correspondendo a uma oferta de 58,1\%, na forte dependência do petróleo, representando $44 \%$ da produção total, já os $41,9 \%$, são ofertados pela produção de fontes renováveis, com destaque à produtos da cana-de-açúcar, com uma produção total em 2015 de 50,4 milhões TEP, representando 17,6\% da produção de energia primária no Brasil (EPE, 2015).

A evolução da participação na produção de energia dos produtos da cana-deaçúcar representa grande vantagem competitiva, uma vez que representa geração de valor e renda, se destacando em relação ao etanol produzido por meio do milho nos EUA, tanto na produção quanto com relação ao balanço energético (CHAGAS et al.,2008;HOFFMANN, 2006).

$O$ avanço dessa monocultura tem se intensificado devido ao crescimento da fabricação de motores flexfuel no país. A expansão do uso de motores movidos à combustíveis de fontes renováveis se deu por conta da crise do petróleo do ano 2000 e o consequente aumento de preços provocado pela crise. O Brasil buscou essa alternativa para contornar a crise e, se beneficiou por possuir condições climáticas favoráveis e pela produção de cana-de-açúcar ser economicamente viável para o país (FOREST et al., 2014).

A expansão da monocultura tem se concentrado na região Centro-Sul do Brasil, e o estado de São Paulo se destaca, sendo responsável por $60 \%$ da quantidade de cana-de-açúcar produzida no Brasil e, por $87 \%$ da região Sudeste (CHAGAS et al., 2008).

Dados do Instituto de Economia Agrícola (IEA) e da Coordenadoria de Assistência Técnica Integral (CATI) demonstraram que houve um crescimento expressivo da área com produção de cana-de-açúcar no estado de São Paulo entre os anos de 2005 e 2010. Em área o crescimento foi de $64,56 \%$ e em produção de 68,7\% (TORQUATO; RAMOS, 2013). Atribui-se esse aumento à expansão da demanda por motores flexfuel e principalmente pela publicidade que os biocombustíveis tiveram nos últimos tempos, abarcando as soluções para a crise energética e os desafios em solucionar os problemas das mudanças climáticas ocorridas nos últimos anos (DUFT; PICOLI, 2018).

Ao mesmo tempo que o país tem esse evidente potencial para produzir canade-açúcar para abastecer o mercado nacional com combustível, energia e outros produtos que a utilizam como matéria-prima; menciona-se a questão da segurança alimentar, que entende-se como a produção de alimentos necessários para abastecer a população com diversidade nutricional, em quantidades suficientes $e$ com qualidade (FOREST et al., 2014). Vale ressaltar que o Brasil é considerado um dos maiores produtores de alimentos do mundo, em função da sua extensão territorial, da faixa de clima que o país se inclui e das tecnologias aplicadas para produção de culturas agrícolas (COELHO, 2001).

Com preocupação de mediar a importância da distribuição de terras destinadas à produção de cana-de-açúcar e produção de alimentos, é relevante o entendimento sobre as quantidades de terras agricultáveis para atender à todas as demandas do país, mas para isso, é importante observar mundialmente como a questão da distribuição da terra tem se dado, para posteriormente verificar as condições do Brasil. A distribuição das terras no mundo na TABELA 3. 
TABELA 3. Distribuição das terras no mundo (milhões de hectares).

\begin{tabular}{|c|c|c|c|c|}
\hline Terras & 1961 & $\%$ & 2014 & $\%$ \\
\hline 1. Área Agrícola & $4.457,98$ & 34,15 & $4.900,2$ & 37,67 \\
\hline 1.1 Pastagens & $3.077,89$ & 23,57 & $3.315,55$ & 25,49 \\
\hline 2. Floresta & $4.374,16$ & 33,5 & $4.002,44$ & 30,77 \\
\hline 3. Outros Usos & $4.223,56^{\star}$ & 32,23 & $4.106,46^{\star}$ & 31,66 \\
\hline Total & $13.055,7$ & 100 & $13.009,1$ & 100 \\
\hline
\end{tabular}

Fonte: Elaborada pelos autores. Fonte: (FAO, 2014). *Dados Ajustados.

Observa-se na TABELA que a quantidade de terras disponíveis para a agricultura representa $37,67 \%$ das terras disponíveis no mundo, dos quais $25,49 \%$ estão sendo ocupadas com pastagens e as florestas representam 30,77\% dessas terras (FAO, 2014).

No Brasil, essa distribuição das terras se comporta de maneira diferente, uma vez que o total de terras destinada às lavouras é de $21 \%$, enquanto que a parte destinada à pecuária (pastagens) é de $49 \%$ e as florestam ficam com apenas $29 \%$ de representatividade observada no FIGURA.

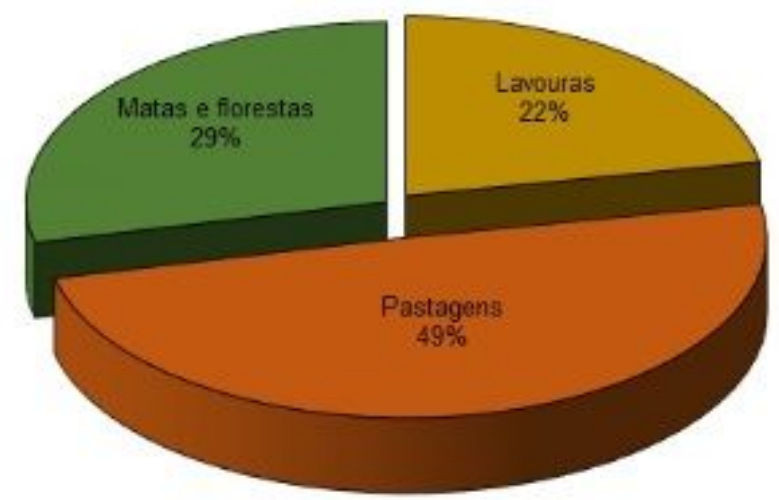

FIGURA 6. Distribuição das terras no Brasil. Fonte: (IBGE, 2006).

Nesse sentido a atividade pecuária é impactante no cenário de distribuição de terras. Contrastando com esse cenário, em uma abordagem realizada no estado de São Paulo, estado este que tem representatividade no cenário de disputa por terras e consequentemente de disponibilidade de alimentos, a atividade pecuária pouco evolui em eficiência produtiva, constatado pela observação comparativa entre a área destinada à atividade em relação a quantidade de cabeças de gado (LOURENZANI; CALDAS, 2014).

Outra questão que vem sendo debatida academicamente é com relação ao uso apropriado da terra, abordando dois pontos: se a terra deve ser utilizada para garantir a biodiversidade ou se a produção agrícola deve dividir espaço com a produção não agroalimentar. Em regiões onde é predominante a atividade rural familiar, essa mudança na forma de uso da terra pode levar a problemas relacionados à segurança alimentar, pois afeta a capacidade de produção local, impacta no preço da terra e na renda agrícola da população da região (LOURENZANI; CALDAS, 2014).

Por outro lado, em um cenário nacional determinados produtos não tiveram impactos em suas produtividades com o aumento da área destinada a cana-de- 
açúcar, como por exemplo, a pecuária de corte, que não vem sofrendo quedas na produção de carne, ao contrário da pecuária leiteira que sofreu impactos. Mesmo que a produção absoluta de alimentos se mantenha, não indica que as mudanças no uso da terra são inexistentes e que não provocam impactos sobre a produção e o acesso aos alimentos em nível regional (PEROSA, 2014).

Por outro lado, perceberam que houve aumento na área expandida na mesorregião do Sudoeste do Mato Grosso do Sul e que essa expansão foi heterogênea e alterou a composição agrícola da região uma vez que foi evidenciado a substituição de culturas como soja trigo e arroz em detrimento à cana-de-açúcar, entre os anos de 2003 e 2013. Nesse sentido também foi observado a redução nas áreas de pastagens nesse período (BRASIL et al., 2016).

No estado Goiás houve aumento de $302 \%$ na área plantada de cana-deaçúcar, entre os anos de 2005 e 2012. As áreas substituídas foram preferencialmente as destinadas a agricultura e posteriormente à pecuária, indicando um processo de substituição de culturas alimentares. (ALMEIDA et al., 2016).

De acordo com Chagas et al. (2008) não é possível afirmar que um aumento na produção de cana-de-açúcar impacte positivamente no preço da terra e, consequentemente na sua disponibilidade para produções agroalimentares. Esse aumento no preço da terra pode ser provocado pelo aumento da demanda por qualquer produto vindo do campo. $\mathrm{E}$, a relação dos preços dos alimentos com o aumento da produção de cana-de-açúcar é positiva, porém, é preciso observar todo o cenário econômico, da dinâmica industrial e das inovações tecnológicas.

Nesse sentido, Rodrigues e Abreu, (2017) reforçam essa ideia quando analisam a questão da disputa por terra. Diante da quantidade de terras aráveis que - Brasil possui as porcentagens destinadas à produção de matérias primas para suprir a demanda energética não afetam a produção de alimentos.

Em contraposição aos argumentos apresentados, e apresentando um panorama preocupante com relação à alguns itens básicos da alimentação, Forest et al., (2014) faz uma crítica com relação às políticas públicas existentes para as produções de culturas para biocombustíveis comparadas com a produção de culturas destinadas ao provento da segurança alimentar. A primeira teve seus objetivos de expansão e as próprias políticas completamente realizados. Ainda com relação à produção de culturas para biocombustíveis, os autores mencionam o exemplo dos estados de São Paulo, Alagoas e Pernambuco, que de 1976 a 1980 aumentaram a produção de cana-de-açúcar e as áreas de cultivos de arroz, mandioca, milho e feijão foram reduzidas. Nesse sentido, entende-se que há uma competição pelo uso das áreas e isso pode levar ao deslocamento da fronteira agrícola para outras regiões (FOREST et al., 2014).

Quando se fala nas fronteiras agrícolas questões como preocupação ambiental devido à possíveis desmatamentos e o provimentos de alimentos regionais ficarem comprometidos vem à tona. Nesse sentido, (ABDALA; RIBEIRO, 2011) comentam pontos importantes relacionados à essas questões. Para os autores, que analisaram como se deu esse deslocamento no estado de Goiás, no momento de expansão da cultura da cana-de-açúcar em 2003, motivada pelo aumento da produção de veículos biocombustíveis. O aumento na área de produção de cana-de-açúcar foi de cerca de $10 \%$, o que não representou uma diminuição nas terras agricultáveis, ocupadas com culturas alimentares. Ocorre deslocamento de culturas de pastagens, nem tanto especializadas na produção de alimentos, concentrando espacialmente a produção de cana-de-açúcar e consequentemente 
causando desflorestamentos. É evidenciado também que a área destinada a cultura da cana-de-açúcar tem um efeito negativo sobre as áreas destinadas à produção de alimentos, principalmente da soja e de outras culturas temporárias, importantes para a segurança alimentar.

Para atender as demandas de garantia de alimentos para a população e fontes de energia para provimento do país, sabe-se que existe uma competição por água, terra e energia e essa concorrência se dá entre a produção de alimentos e a produção de energia por fontes renováveis, os biocombustíveis. A produção de biocombustíveis no Brasil é de 50 bilhões de litros por ano, e, de biodiesel, de 5 bilhões de litros por ano (LEITE; LEAL, 2007; UNCTAD, 2008; ANAP, 2017).

Diante do cenário competitivo que se forma entre as produções de alimentos e matérias primas para a produção de etanol, é importante destacar que no Brasil esse cenário tem um papel importante na formação dos preços dos produtos alimentícios, principalmente no que tange a disputa pelas terras utilizadas para tal. Para (MATOS et al., 2008) a produção de etanol à partir da cana-de-açúcar não tem relação direta com os preços e a disponibilidade dos alimentos no Brasil, e isso pode ser explicado observando que houve aumento na produção de commodities agrícolas, independente da produção de etanol.

Nesse sentido, ainda há espaços nas terras brasileiras para todas as culturas se desenvolverem e crescerem. Não é um fator de preocupação para o país a questão da disponibilidade de terras para o cultivo de culturas destinadas ao provimento de alimentos para a população e para a produção de biocombustíveis (MATOS et al., 2008).

Mundialmente existe uma preocupação com a garantia de alimentos em quantidade e qualidade para a população, nem tampouco as inovações tecnológicas, acadêmicas e o fato do deslocamento das fronteiras agrícolas garantir a segurança alimentar, e sim no aumento da produtividade das terras já cultivadas sem agredir o meio ambiente para não agravar ainda mais a questão do aquecimento global (BUAINAIN et al.,2016).

\section{CONSIDERAÇÕES FINAIS}

Dados da ONU mostram que haverá um expressivo aumento da população mundial até 0 ano de 2100, demandando um alto nível de urbanização. A preocupação de Malthus mostra-se pertinente ao fato da fome mundial em decorrência do aumento populacional, fazendo jus à produção de alimentos e energias limpas, vigorando-se como importantes a cultura da cana-de-açúcar e a soja para produção de biocombustíveis, bioetanol e biodiesel, comercializados em larga escala após a inserção dos veículos flexfuel no Brasil.

Concomitante a esse processo, surgiu a preocupação com a disputa por terras para produção de alimentos e matérias primas para a produção de biocombustíveis. Nesse sentido, durante a revisão de literatura foi possível observar que existem diferentes visões que marcam esse contexto. A principal vertente está relacionada à melhoria na produtividade das terras destinadas à produção de alimentos, através da intensificação do uso de tecnologias, uma vez que essas terras estão perdendo espaço para as produções de matérias primas que se destinarão à produção de biocombustíveis. Dentro desse contexto, existe também uma preocupação com a possibilidade de haver um desflorestamento para que a agricultura possa evoluir e atender a todas as demandas de aumento populacional, e, embutido a isso existe uma preocupação de cunho ambiental muito expressiva e 
que é muito debatida atualmente no cenário da evolução do efeito estufa e outras questões ambientais.

Cabe ressaltar que existe uma preocupação com as divisões de terras para as duas demandas mencionadas nesse trabalho, alimentos e energia, e que é expressivo o número de pequenas propriedades rurais familiares que se diluíram no cenário da expansão da produção de cana-de-açúcar. O ponto chave está relacionado com a diversidade alimentar que a agricultura familiar consegue trazer para as populações, e que está se perdendo com essa expansão.

Por se tratar de temas dinâmicos e abertos a mudanças em seus índices de evolução como a Segurança Alimentar e a Produção de Energia, o estudo realizado não teve o objetivo de ser conclusivo, pelo contrário, espera-se que o mesmo auxilie outros estudiosos em pesquisas futuras, e que incluindo novos elementos, possam tornar o estudo mais rico, mais amplo e detalhado.

\section{REFERÊNCIAS}

ABDALA, K. D. O.; RIBEIRO, F. L. Análise dos impactos da competição pelo uso do solo no estado de Goiás durante o período 2000 a 2009 provenientes da expansão do complexo sucroalcooleiro. Revista Brasileira de Economia, v. 65, n. 4, p. 373400, 2011. Disponível em: <http://dx.doi.org/10.1590/S0034-71402011000400004>. Acesso em 13 mai. 2017.

ABIOVE - Associação Brasileira das Indústrias de Óleos Vegetais. Dados de produção e entrega de biodiesel no Brasil, 2017. Disponível em: <http://www.abiove.org.br/site/index.php?page=estatistica\&area=NC0yLTE>. Acesso em 11 jun. 2017.

ABRANDH - Ação Brasileira pela Nutrição e Direitos Humanos. O direito humano à alimentação adequada e o sistema nacional de segurança alimentar e nutricional / Organizadora, Marília Leão, Brasília: ABRANDH, p. 263, 2013. Disponível em: <http://www.oda-alc.org/documentos/1374763097.pdf>. Acesso em 03 jun. 2017.

ALMEIDA, R. T. S., et al. Distribuição territorial da cana-de-açúcar em relação ao uso da terra e ao zoneamento agroecológico da cana no estado de Goiás. Revista de Ciências Ambientais, v.10, n.1, p. 123-133, 2016. Disponível em: <http://dx.doi.org/10.18316/1981-8858.16.26>. Acesso em 26 jun. 2018.

ANFAVEA - Associação Nacional dos Fabricantes de Veículos Automotores. Anuário da indústria automobilística brasileira. São Paulo, 2017. Disponível em: $<$ http://www.virapagina.com.br/anfavea2017/files/assets/common/downloads/publicat ion.pdf>. Acesso em: 05 mai. 2018.

BASTOS, V. D. Etanol, alcoolquímica e biorrefinarias. BNDES Setorial, Rio de Janeiro, n. 25, p. 5-38, 2007. Disponível em: <https://web.bndes.gov.br/bib/jspui/bitstream/1408/2527/1/BS\%2025\%20Etanol\%2c $\% 20$ Alcoolqu\%C3\%ADmica\%20e\%20Biorrefinarias_P.pdf>. Acesso em: 06 mai. 2017.

BUAINAIN, A. M.; GARCIA, J. R.; VIEIRA, P. A. O desafio alimentar no século XXI. Estudos Sociedade e Agricultura, v. 2, n. 24, p. 497-522, 2016. Disponível em: <http://r1.ufrrj.br/esa/V2/ojs/index.php/esa/article/view/784/458>. Acesso em 29 mai. 2017. 
CHAGAS, A. L. S.; TONETO JUNIOR, R.; AZZONI, C. R. Teremos que trocar energia por comida? Análise do impacto da expansão da produção de cana-deaçúcar sobre o preço da terra dos alimentos. Revista Economia, v. 6, n. 4, p. 39-41, 2008. Disponível em: <http://www.anpec.org.br/revista/vol9/vol9n4p39_61.pdf>. Acesso em 21 mai. 2017.

COELHO, C. N. 70 anos de política agrícola no Brasil (1931 - 2001). Revista de Política Agrícola, v. 10, n. 3, p. 59, 2001. Disponível em: $<$ https://seer.sede.embrapa.br/index.php/RPA/article/view/237/200>. Acesso em 25 de mai. 2017.

CONAB - Companhia Nacional de Abastecimento. Acompanhamento da safra brasileira de cana-de-açúcar. Brasília: Conab, v. 2 - safra 2015/2016, n. 3, p. 1-65, $2015 . \quad$ Disponível em: <http://www.conab.gov.br/OlalaCMS/uploads/arquivos/15_12_17_09_03_29_boletim cana_portugues_-_3o_lev_-_15-16.pdf>. Acesso em: 05 mai. 2017.

CONAB - Companhia Nacional de Abastecimento. Acompanhamento da safra brasileira de grãos. Monitoramento Agrícola - Safra 2017, v. 4, n. 7, p. 1-98, 2017. Disponível em: <http://www.conab.gov.br/OlalaCMS/uploads/arquivos/17_04_17_17_20_55_boletim _graos_abr_2017.pdf>. Acesso em 01 jun. 2017.

CONAB - Companhia Nacional de Abastecimento. Séries históricas de área plantada, produtividade e produção, relativas às safras 1976/77 a 2015/16, 2017. Disponível em: $<$ http://www.conab.gov.br/conteudos.php?a=1252\&ordem=produto\&Pagina_objcmsc onteudos=3\#A_objcmsconteudos > . Acesso em 12 jun. 2017.

DUFT, D. G.; PICOLI, M. C. A. Uso de imagens do sensor modis para identificação da seca na cana-de-açúcar através de índices espectrais. Revista Scientia Agraria. v. $19 ; \quad$ n. $1 ; \quad$ p. 52-63, 2018. Disponível em: <http://dx.doi.org/10.5380/rsa.v19i1.54005>. Acesso em 15 jun. 2018.

EPE - Empresa de Pesquisa Energética. Balanço Energético Nacional 2016: ano base 2015. Rio de Janeiro: EPE, 2016. 292 p. Disponível em: <http://www.epe.gov.br/Estudos/Paginas/default.aspx?CategorialD=347>. Acesso em: 06 mai. 2017.

EPE - Empresa de Pesquisa Energética. Balanço energético nacional: Séries históricas, Capítulo 1 (Análise Energética e Dados Agregados), 2015. Disponível em: <https://ben.epe.gov.br/BENSeriesCompletas.aspx>. Acesso em 12 mai. 2017.

FAO - Food and Agriculture Organization of the United Nations. Crop statistics: Production Quantity and Area harvested sugar cane. 2016. Disponível em: <http://www.fao.org/faostat/en/\#data/QC>. Acesso em: 10 mai. 2017.

FAO - Food and Agriculture Organization of the United Nations. Faostat Land of Brazil: Agricultural area. 2014.2 Disponível em: <http://www.fao.org/faostat/en/\#data/RL>. Acesso em: 10 mai. 2017.

FOREST, R.; FOREST, M.; COSTA, J. S.; RUVIARO, C. F. Segurança alimentar e sua relação com a expansão do programa de biocombustíveis. Revista de Política Agrícola, v. 23, n. 3, p. 99-111, 2014. Disponível em: $<$ https://ainfo.cnptia.embrapa.br/digital/bitstream/item/114659/1/Segurancaalimentar.pdf>. Acesso em 03 jun. 2017. 
FRANCO, A. Além da renda: a pobreza brasileira como insuficiência de desenvolvimento. Inst. de Política: Brasília, 260p, 2000.

FURTADO, C. Desenvolvimento e subdesenvolvimento. Rio de Janeiro: Fundo de Cultura, 1961.

GURGEL, A. C. Impactos da política americana de estímulos aos biocombustíveis sobre a produção agropecuária e o uso da terra. Revista de Economia e Sociologia Rural: Piracicaba, v. 49, n. 01, p. 181-214, 2011. Disponível em: <http://dx.doi.org/10.1590/S0103-20032011000100008>. Acesso em: 08 mai. 2017.

HOFFMANN, R. Segurança alimentar e produção de etanol no brasil. Segurança alimentar e nutricional, v. 13 n. 2, p. 1-5, 2006. Disponível em: <https://doi.org/10.20396/san.v13i2.1827>. Acesso em 03 jun. 2017.

KOHLHEPP, G. Análise da situação da produção de etanol e biodiesel no Brasil. Estudos Avançados., São Paulo, v. 24, n. 68, p. 223-253, 2010. Disponível em <http://dx.doi.org/10.1590/S0103-40142010000100017>. Acesso em 04 jun. 2017.

LEITE, R. C. C.; LEAL, M. R. L. V. O biocombustível no Brasil. Novos estudos. CEBRAP, São Paulo, n. 78, p. 15-21, 2007. Disponível em: <http://dx.doi.org/10.1590/S0101-33002007000200003>. Acesso em: 08 mai. 2017.

LOPES, M. L.; PAULILLO, S. C. de L.; GODOY, A.; CHERUBIN, R. A.; LORENZI, M. S.; GIOMETTI, F. H. C.; BERNARDINO, C. D.; AMORIM NETO, H. B. de; AMORIM, H. V. de. Ethanol Production in Brazil: A Bridge between Science and Industry. Brazilian Journal of Microbiology, v. 47, p. 64-76, dez. 2016. Disponível em: <http://dx.doi.org/10.1016/j.bjm.2016.10.003 >. Acesso em 26 jun. 2017.

LOURENZANI, W. L.; BERNARDO, R.; CALDAS, M. M. Produção de biocombustível e alteração da composição agropecuária no Centro-Oeste do Brasil. Interações (Campo Grande), v. 17, n. 4, p. 561-575, 2016. Disponível em: <http://dx.doi.org/10.20435/1984-042x-2016-v.17-n.4(02)>. Acesso em 26 jun. 2017.

LOURENZANI, W. L.; CALDAS, M. M. Mudanças no uso da terra decorrentes da expansão da cultura da cana-de-açúcar na região oeste do estado de São Paulo. Revista Ciência Rural, v. 44, n. 11, p. 1980 - 1987, 2014. Disponível em: <http://dx.doi.org/10.1590/0103-8478cr20140186>. Acesso em 27 mai. 2017.

MALTHUS, T. R. Princípios de economia política e considerações sobre sua aplicação prática: Ensaio sobre a população. Tradução de Regis de Castro Andrade, Dinah de Abreu Azevedo e Antônio Alves Cury. São Paulo: Nova Cultural, 1996. Disponível em: <https://edisciplinas.usp.br/pluginfile.php/3306652/mod_resource/content/1/malthus $\% 20 \% 281996 \% 29 \% 20$ principios\%20de\%20economia\%20politica.pdf $>$. Acesso em 01 jun. 2017.

MARTINELLI, L. A.; FILOSO, S. Expansion of sugarcane ethanol production in brazil: environmental and social challenges. Ecological Applications, v. 18, p. 885-898, 2008. Disponível em: <http://onlinelibrary.wiley.com/doi/10.1890/07-1813.1/full>. Acesso em: 09 mai. 2017.

MATOS, M. A.; NINAUT, E. S.; CAIADO, R. C.; SALVI, J. V. A Elevação dos Preços das Commodities Agrícolas. Revista Informações Econômicas, São Paulo, v. 38, n. 9, p. 68-83, 2008. Disponível em: <ftp://ftp.sp.gov.br/ftpiea/publicacoes/tec70908.pdf>. Acesso em 29 mai. 2017. 
MILANEZ, A. Y. et al. A produção de etanol pela integração do milho-safrinha às usinas de cana-de-açúcar: avaliação ambiental, econômica e sugestões de política. Revista do BNDES, Rio de Janeiro, n. 41, p. 147-207, 2014. Disponível em: $<$ https://web.bndes.gov.br/bib/jspui/bitstream/1408/2496/1/RB\%2041\%20A\%20produ \%C3\%A7\%C3\%A30\%20de\%20etanol_P.pdf>. Acesso em: 12 mai. 2017.

MITCHELL, D. A Note on Rising Food Prices. Policy Research Working Paper 4682. The World Bank Development Prospects Group, 2008. Disponível em: <https://doi.org/10.1596/1813-9450-4682>. Acesso em: 15 mai. 2017.

MMA - Ministério do Meio Ambiente. Dinâmica populacional e agenda ambiental brasileira: distribuição espacial, desastres naturais e políticas de adaptação. Brasília:

UNFPA, 2014.

Disponível

em:

<http://www.mma.gov.br/publicacoes/desenvolvimento-

sustent\%C3\%A1vel/category/148-geral>. Acesso em 01 jun. 2017.

MME - Ministério de Minas e Energia. Boletim mensal dos combustíveis renováveis. ed. 95, dezembro, 2015.2 Disponível em: <http://www.mme.gov.br/documents/1138769/1732805/Boletim+DCR+n\%C2\%BA+9 5+-+dezembro+de+2015.pdf/3f3e833b-ef26-43a6-a65f-7c1a7918e6e3>. Acesso em 11 jun. 2017.

NASS, L. L.; PEREIRA, P. A. A.; ELLIS, D. Biofuels in Brazil: an overview. Crop science, v. 47, n. 6, p. 2228-2237, 2007. Disponível em: <https://www.crops.org/publications/cs/articles/47/6/2228>. Acesso em: 09 mai. 2017.

OCDE-FAO - Organização de Cooperação e de Desenvolvimento Econômico e Food and Agriculture Organization of the United Nations. Perspectivas agrícolas no Brasil: desafios da agricultura brasileira 2015-2024. Capítulo 2. Agricultura brasileira: perspectivas e Desafios. Brasil, 2015. Disponível em: <http://www.fao.org.br/download/PA20142015CB.pdf>. Aceso em 03 fev. 2017

ONU - Organização das Nações Unidas. The Universal Declaration of Human Rights. $2017 . \quad$ Disponível em: <http://www.ohchr.org/EN/UDHR/Documents/UDHR_Translations/eng.pdf>. Acesso em 31 mai. 2017.

ONU - Organização das Nações Unidas. Transformando nosso mundo: a agenda 2030 para o desenvolvimento sustentável. Objetivos do desenvolvimento Sustentável, 2016. Disponível em: <https://nacoesunidas.org/wpcontent/uploads/2015/10/agenda2030-pt-br.pdf>. Acesso em 03 jun. 2017.

ONU - Organização das Nações Unidas. World population prospects 2015: Graphs, 2015. Disponível em: <https://esa.un.org/unpd/wpp/Graphs/Probabilistic/POP/TOT/>. Acesso em 20 mai. 2017.

OSAKI, M.; BATALHA, M. O. Produção de biodiesel e óleo vegetal no Brasil: realidade e desafio, Organizações Rurais \& Agroindustriais, Lavras, v. 13, n. 2., p. 227-242, $2011 . \quad$ Disponível em: <http://200.131.250.22/revistadae/index.php/ora/article/view/349/313>. Acesso em 12 jun. 2017.

PERES, J. R. R., JUNIOR, E. F., GAZZONI, D. L. Biocombustíveis uma oportunidade para o agronegócio brasileiro. Revista de Política Agrícola, v. 14, n. 1, p. 31-41, 2005. 
<https://seer.sede.embrapa.br/index.php/RPA/article/view/528/478>. Acesso em: 07 mai. 2017.

PEROSA, B. B. Impactos da expansão canavieira. AgroANALYSIS, São Paulo, v. 34, n. 01, p. 24-26, 2014. Disponível em: <http://bibliotecadigital.fgv.br/ojs/index.php/agroanalysis/article/view/27208>. Acesso em: 13 jun. 2017.

RFA - Renewable Fuels Association. Industry Statistics: World Fuel Ethanol Production, $2016 . \quad$ Disponível em: <http://www.ethanolrfa.org/resources/industry/statistics/\#1454099103927-61e598f77643 >. Acesso em: 07 mai. 2017.

RODRIGUES, O. C. S.; DE ABREU, Y.V. Características da posse e uso de terras relacionadas às culturas agrícolas destinadas a produção de agroenergia no Brasil. (Biodiesel e Etanol). DESAFIOS, 2017, 3: 12-21. Disponível em: <https://doi.org/10.20873/uft.2359-3652.2016v3nespp12>. Acesso em 27 jun. 2017.

SHIKIDA, P. F. A. Evolução e fases da agroindústria canavieira no Brasil. Revista de Política Agrícola, v. 23, n. 4, p. 1-15, 2014. Disponível em: $<$ https://seer.sede.embrapa.br/index.php/RPA/article/view/953/843>. Acesso em: 02 jun. 2017.

SILVA, J. A. Avaliação do programa nacional de produção e uso do biodiesel no Brasil-PNPB. Revista de Política Agrícola, v. 22, n. 3, p. 18-31, 2013. Disponível em: <https://seer.sede.embrapa.br/index.php/RPA/article/view/763/720>. Acesso em: 20 mai. 2017.

SILVA, S. P. A trajetória histórica da Segurança Alimentar e Nutricional na Agenda Política Nacional: projetos, descontinuidades e consolidação. Instituto de Pesquisa Econômica Aplicada, Rio de Janeiro, 2014. Disponível em: <http://repositorio.ipea.gov.br/bitstream/11058/3019/1/TD_1953.pdf>. Acesso em 30 mai. 2017.

TAPANES, N. C.; ARANDA, D. A. G.; PEREZ, R. S.; CRUZ, Y. R. Biodiesel no Brasil: matérias primas e tecnologias de produção. Acta Scientiae \&Technicae, v. 1, n. 1, 2013. Disponível em: <https://doi.org/10.17648/uezo-ast-v1i1.11>. Acesso em 11 jun. 2017.

TOLMASQUIM, M. T. Perspectivas e planejamento do setor energético no Brasil. Estudos avançados, v. 26, n. 74, p. 247-260, 2012. Disponível em: <http://dx.doi.org/10.1590/S0103-40142012000100017>. Acesso em: 12 mai. 2017.

TORQUATO, S. A.; RAMOS, R.C. Biomassa da cana-de-açúcar e a geração de bioeletricidade em São Paulo: usinas signatárias ao Protocolo Agroambiental Paulista. Revista Informações Econômicas, São Paulo, v. 43, n. 5, 2013. Disponível em: <http://www.iea.sp.gov.br/ftpiea/publicacoes/ie/2013/tec6-1013.pdf>. Acesso em 04 jun. 2017.

UNCTAD - United Nations Conference on Trade and Development. Biofuel production technologies: status, prospects and implications for trade and development. New York and Geneve, 2008. Disponível em: <http://unctad.org/en/docs/ditcted200710_en.pdf>. Acesso em: 05 mai. 2017. 
USDA - United States Department of Agriculture. Sugar: World Markets and Trade. 2016. Disponível em: <http://usda.mannlib.cornell.edu/usda/current/sugar/sugar-1117-2016.pdf>. Acesso em: 01 mai. 2017. 